\title{
Regionally disturbed production of cartilage proteoglycans in malformed fetuses from diabetic rats
}

\author{
E. Unger ${ }^{1}$ and U.J. Eriksson ${ }^{2}$ \\ ${ }^{1}$ Department of Veterinary Medical Chemistry, Swedish University of Agricultural Sciences, and \\ ${ }^{2}$ Department of Medical Cell Biology, University of Uppsala, The Biomedical Centre, Uppsala, Sweden
}

Summary. Fetuses from normal and manifestly diabetic rats were obtained on pregnancy day 20 . The fetuses from the diabetic rats were of normal or malformed morphology. Three tissue groups were dissected free; costal cartilage, the hard tissue of the rear, and of the frontal portion of the mandible. These tissues were maintained in vitro for $24 \mathrm{~h}$ during which time they were labelled with $\left[{ }^{35} \mathrm{~S}\right]$ sulphate. After the culture period the tissues were extracted with guanidine $\mathrm{HCl}$ and the resulting residues were further extracted with alkali. The culture medium was saved and its macromolecular content was compared to that of the extracts. The proteoglycans recovered in all extracts eluted at two distinct positions after chromatography on a Sepharose CL-2B column (peak I: $\mathrm{K}_{\mathrm{av}}$ $\sim 0.4$, and peak II: $\mathrm{K}_{\mathrm{av}} \sim 0.8$ ), but the elution patterns were markedly different in extracts from various tissues. Thus, in rib cartilage, the majority of the labelled proteoglycans were located in peak I $(\sim 90 \%)$ with no difference between extracts of fetuses from normal and diabetic pregnancies. In extracts of mandibular cartilaginous tissue from normal rat offspring the peak I percentage (60-80\%) was lower than in the rib cartilage extracts. In the extracts from the frontal portion of malformed mandibles of fetuses of diabetic rats, the peak I percentage $(35 \pm 21 \%)$ was the lowest of all recorded and the only one to significantly differ from the other percentages in its (the frontal mandible) group. The results show an association between a congenital malformation, micrognathia, and a disturbance in the production of chondroitin sulphate proteoglycans in the malformed region.

Key words: Rat, teratology, diabetic pregnancy, mandible, congenital malformation, proteoglycans, proteoglycan synthesis, chondroitin sulphate, costal cartilage.
Previous studies have demonstrated that diabetes affects the metabolism of several connective tissue components [1], including the heparan sulphate [2] and chondroitin sulphate [3] proteoglycans. The full functional implications of these biochemical changes are at present unclear, but heparan sulphate alterations may hamper normal kidney performance [4], and a disturbed production of chondroitin sulphate proteoglycans may alter chondrocyte function [5]. It is also conceivable that maternal diabetes may induce proteoglycan disturbances in the offspring and thereby affect the maturation of chondrocytes leading to alterations of the cartilage model of the future osseous skeleton [6-9].

The fetuses of the rats used in the present study (denoted $U$ rats, $[10-11]$ ) display skeletal malformations when the rat mother is manifestly diabetic, and we have previously shown that diabetic adult rats of this strain have an altered composition of chondroitin sulphate proteoglycans in their rib cartilage [3]. In addition, we have demonstrated that chondrocytes from the mandibular arch region of embryos of diabetic $U$ rats are very sensi- tive to a diabetes-like environment in vitro, since their development into mature chondrocytes is hampered when they are exposed to elevated ambient concentrations of glucose and $\beta$-hydroxybutyrate [12]. This finding suggests a specific and diabetes-associated metabolic vulnerability, which parallels the teratological sensitivity of this particular embryonic cell population.

The aim of the present investigation was to characterize the production of proteoglycans in mandibles from fetuses from diabetic $\mathrm{U}$ rats with and without mandibular malformations. The elution profiles were compared with the production pattern in rib cartilage, a tissue that does not show congenital malformations in rat diabetic pregnancy.

\section{Materials and methods}

Streptozotocin was a gift from the Upjohn Co., (Kalamazoo, Mi., USA). N-ethylmaleimide, benzamidine, $\varepsilon$-amino-n-caproic acid, DNP-alanine and chondroitinase ABC (chondroitin sulphate lyase, 


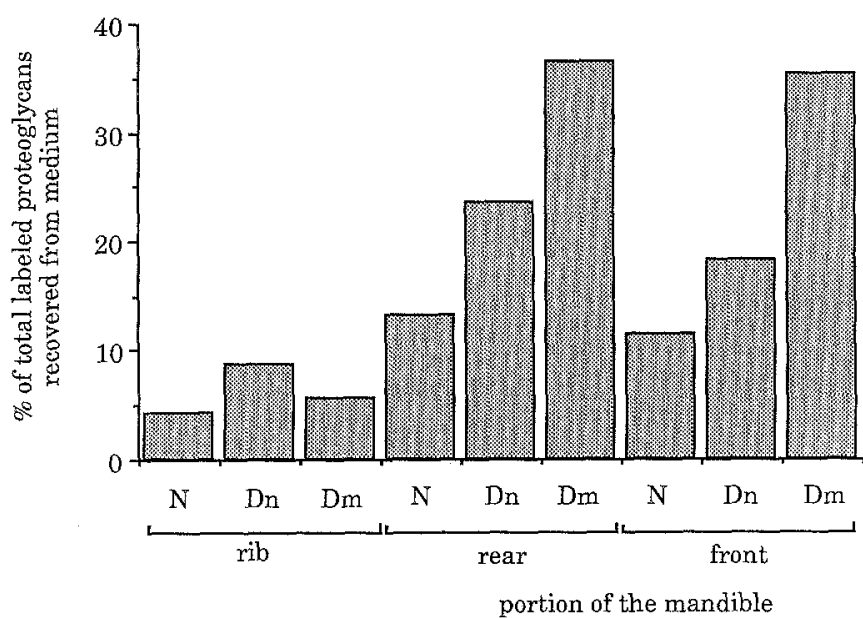

Fig. 1. Percentage of total $\left[{ }^{35} \mathrm{~S}\right]$ sulphate-labelled macromolecules found in the culture medium from organ cultures of rib and mandibular cartilage from day-20-fetuses of normal (N) and diabetic (D) rat mothers. The fetuses of $D$ rats show normal morphology (n), or exhibit mandibular malformations $(\mathrm{m})$. Single determinations

EC 4.2.2.4) were obtained from Sigma Chemical Co., (St.Iouis, Mo., USA). Inorganic $\left[{ }^{35} \mathrm{~S}\right]$ sulphate (carrier-free) was from The Radiochemical Centre, (Amersham, Bucks, UK). Sepharose CL2B, Sepharose CL-6B, Sephadex G-50 and Blue Dextran were purchased from Pharmacia Fine Chemicals, (Uppsala, Sweden).

\section{Induction of diabetes and pregnancy}

Virgin female Sprague-Dawley rats (about 12 weeks old) of the substrain $U[10,11]$ were used for the experiment. The rats were given a single injection of $40 \mathrm{mg} / \mathrm{kg}$ streptozotocin [13] into the tail vein 4-6 weeks prior to the experiment. The streptozotocin was dissolved in $0.01 \mathrm{~mol} / \mathrm{l}$ citrate buffer, $\mathrm{pH} 4.5$. Animals with a serum glucose concentration in excess of $20 \mathrm{mmol} / \mathrm{l}$ one week after the injection were considered to be diabetic, the control animals were not injected and had a serum glucose concentration below $6 \mathrm{mmol} / \mathrm{l}$.

Both control and diabetic females were caged overnight with non-diabetic males, the mating commenced in the diabetic animals $7-10$ days after the injection of streptozotocin. The day sperm were found in a morning vaginal smear was designated gestational day 0 .

\section{In vitro labelling of proteoglycans}

Fetuses from control and diabetic rats were carefully dissected out on day 20 of pregnancy, the fetuses from the diabetic rats were inspected and divided into two groups, normal and malformed. The costal cartilage and the hard tissue of the rear and frontal portions of the mandible (lower jaw) were dissected out and weighed. The sulphate labelling was performed in petri dishes $\left(1 \mathrm{mCi}\left[{ }^{35} \mathrm{~S}\right] \mathrm{sul}\right.$ phate/dish) containing $2 \mathrm{ml}$ Ham's F 10 growth medium with HEPES at $37^{\circ} \mathrm{C}$ swirling at $90 \mathrm{rev} / \mathrm{min}$. After $24 \mathrm{~h}$ the medium was removed and the tissues were immersed in $1 \mathrm{ml}$ of extraction buffer [14] (4 mol// guanidine $\mathrm{HCl}$ in $0.05 \mathrm{~mol} / \mathrm{l}$ acetate buffer $\mathrm{pH} 5.8 \mathrm{con}$ taining $0.2 \%$ Triton $\mathrm{X}-100,1 \mathrm{mmol} / \mathrm{l} \mathrm{N}$-ethylmaleimide, $0.1 \mathrm{~mol} / \mathrm{l}$ $\varepsilon$-amino-n-caproic acid, $5 \mathrm{mmol} / \mathrm{l}$ benzamidine $\mathrm{HCl}$ and $10 \mathrm{mmol} / \mathrm{l}$ EDTA). After a further $24 \mathrm{~h}$ the extracts were dialysed against the extraction buffer. The remainder of the tissues were incubated in $2 \mathrm{ml} 0.5 \mathrm{~mol} / 1 \mathrm{NaOH}$ at $4{ }^{\circ} \mathrm{C}$ for $24 \mathrm{~h}$ followed by neutralization. Medium and alkali extracts were dialysed against a $50 \mathrm{mmol} / \mathrm{l}$ Tris buffer, $\mathrm{pH} 8.0$, prior to the estimation of the amount of macromolecular label per $\mathrm{mg}$ of tissue.
Chondroitinase $\mathrm{ABC}$ digestion of samples and subsequent gel chromatography on Sephadex G-50, were performed as previously described [15] and revealed that $>95 \%$ of the labelled material in the extracts and the culture media was digestible, indicating that the label was present in chondroitin sulphate. Radioactivity was determined in a Beckman LS 3800 scintillation counter (Beckman Instruments Inc., Fullerton, Calif., USA).

\section{Analyticalmethods}

Proteoglycan size: The guanidine extracts were chromatographed in extraction buffer on a Sepharose CL-2B column $(88 \times 0.5 \mathrm{~cm})$. Blue Dextran and DNP-alanine were used to indicate the void volume $\left(\mathrm{V}_{\mathrm{o}}\right)$ and the total volume $\left(\mathrm{V}_{\mathrm{t}}\right)$ of the column.

Polysaccharide chain length estimation: Sample extracts were dialysed against $0.2 \mathrm{~mol} / 1 \mathrm{NaCl}$ and then digested overnight with papain ( $5 \%$ in $1 \mathrm{~mol} / 1 \mathrm{NaCl}, 50 \mathrm{mmol} / 1 \mathrm{EDTA}, 50 \mathrm{mmol} / \mathrm{l}$ cysteine $\mathrm{HCl}$, $25 \mathrm{mmol} / \mathrm{l}$ acetate, $\mathrm{pH} 5.5$ at $37^{\circ} \mathrm{C}$ ). After enzyme digestion the samples were chromatographed on a Sepharose CL-6B column $(1 \times 80 \mathrm{~cm})$, eluted with $0.01 \mathrm{~mol} / 1$ Tris buffer, $\mathrm{pH} 8.0$, containing $0.15 \mathrm{~mol} / \mathrm{l} \mathrm{NaCl}$ and $0.1 \%$ sodium dodecyl sulphate (SDS). Blue Dextran and $\left[{ }^{3} \mathrm{H}\right] \mathrm{H}_{2} \mathrm{O}$ were used as markers for void and total volume, respectively.

Chondroitin sulphate proteoglycan aggregation with hyaluronan: $200 \mu \mathrm{l}$ of guanidine sample extract together with $200 \mu \mathrm{l}(100 \mu \mathrm{g} / \mathrm{ml})$ high molecular weight hyaluronan were mixed and dialysed against $0.5 \mathrm{~mol} / \mathrm{l}$ acetate buffer, $\mathrm{pH} 5.8$ with added protease inhibitors $(2 \mathrm{mmol} / \mathrm{l}$ N-ethylmaleimide, $1 \mathrm{mmol} / \mathrm{l}$ phenylmethylsulphonylfluoride, $1 \mu \mathrm{g} / \mathrm{ml}$ pepstatin and $2 \mathrm{mmol} / \mathrm{LEDA}$ ) for $24 \mathrm{~h}$ and subsequently chromatographed on a Sepharose CL-2B column in the same buffer.

\section{Statistical analysis}

Significant differences between and within groups were estimated by one way analysis of variance (ANOVA) and the applied test was Fischer PLSD [16], at the 95, 99, and 99.9\% significance levels. The statistical analyses were made using the StatView for Macintosh program.

\section{Results}

Less than $15 \%$ of the total $\left[{ }^{35} \mathrm{~S}\right]$ sulphate-labelled macromolecular material was left to be extracted by alkali. The total incorporation of label estimated as radioactivity per mg wet weight was 3-4 times higher in rib than in mandibular tissue (data not shown). However, the incorporation of radioactivity per $\mathrm{mg}$ wet weight was similar in each group, regardless of source of the tissue (i. e. the uptake of label per weight was of the same magnitude in mandibular tissue from offspring of normal rats, as in tissue from nonmalformed and malformed fetuses of diabetic rats). The release of proteoglycans into the medium was highest for mandibles from malformed fetuses, as estimated by the radioactivity found in the medium in percent of total macromolecular labelled material in extracts and medium (Fig. 1). The composition of chondroitin sulphate proteoglycans in cartilaginous tissue from different anatomical locations showed pronounced variations in fetuses with mandibular malformations. Thus, in cartilage extracts from fetal ribs the large (partly aggregating) species 


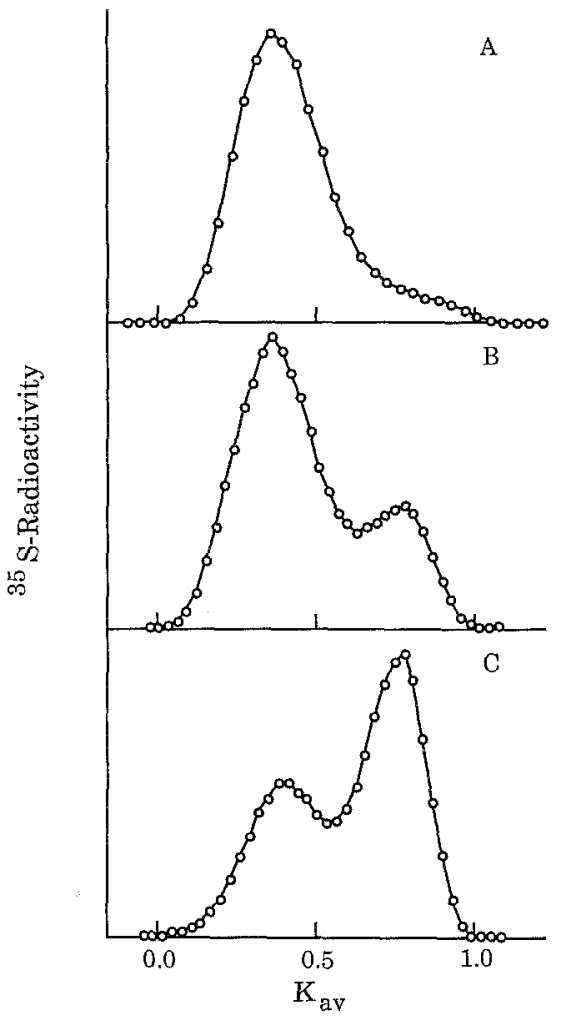

Fig. 2. Cartilage extracts from a malformed fetus chromatographed on Sepharose CL-2B in $4 \mathrm{~mol} / /$ guanidine $\mathrm{HCl}$, separation of proteoglycans into two categories, peak I $\left(\mathrm{K}_{\mathrm{av}} \sim 0.4\right)$ and peak II $\left(\mathrm{K}_{\mathrm{a}} \sim 0.8\right)$. A Rib cartilage extract. B Extract from back part of mandible. C Extract from front part of mandible

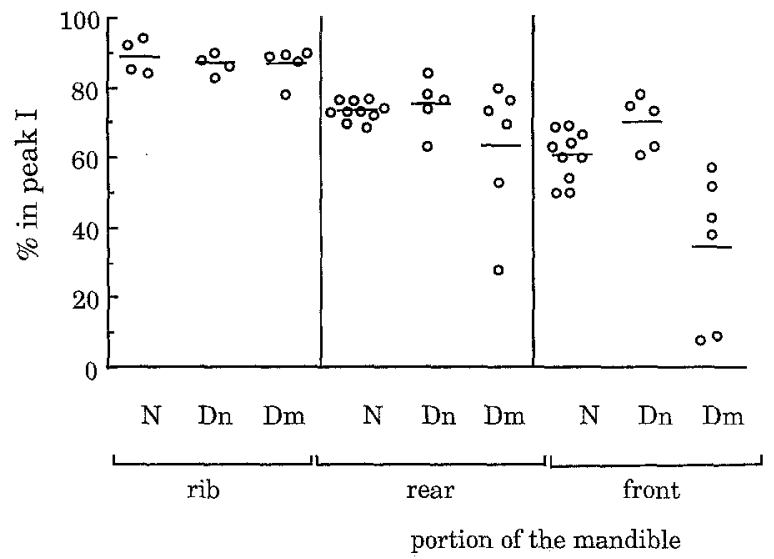

Fig.3. Percentages of extracted proteoglycans from different cartilages eluting in peak I when chromatographed in extraction buffer on Sepharose CL-2B. Normal (N) and diabetic (D) rat mothers, fetuses with normal (n) and malformed (m) mandibular morphology. There is no significant difference at $95 \%$ in analysis of variance (Fischer PLSD) within the groups 'ribs' or 'back part of mandible' whereas the front part of malformed mandibles differs from the other members of its group at $99.9 \%$

dominated (Fig. 2 A). In extracts from mandibular tissue there was a higher proportion of smaller, mainly non-aggregating, proteoglycans present (Fig. $2 \mathrm{~B}$ and $2 \mathrm{C}$ ). The relative proportion of large (peak I) proteoglycans was highest $(\sim 90 \%)$ in rib cartilage, slightly lower in the rear portion of the mandible, and further decreased in the ex- tracts from frontal portions of malformed mandibles (Fig. 3). In tests of significance in the difference in relative proportion of peak I proteoglycans by analysis of variance no significant differences were found within the groups 'ribs' and 'back part of mandible' ( $p>0.05$, ANOVA) whereas in the 'front part of mandible' group the malformed mandibles were significantly different from nonmalformed mandibles whether these were from fetuses of control or diabetic rats $(p<0.001$, ANOVA, [Fig. 3]). (If the two lowest values in the malformed group were excluded the percentage mean remained significantly different from all other values in the group $(p<0.05$, ANOVA))

Proteoglycans recovered from the medium of mandibular organ cultures contained similar amounts of peak I material as the guanidine $\mathrm{HCl}$ extracts while the proportion aggregating proteoglycans were considerably lower ( $\sim 10 \%$ of total vs $\sim 30-40 \%$ in extracts). No differences between medium proteoglycans from frontal and rear portions of the mandibles or normal and malformed mandibles were noted (data not shown).

When guanidine $\mathrm{HCl}$ extracts from front parts of the mandibles were incubated with hyaluronan under associating conditions and subsequently chromatographed, a large proportion of the proteoglycans bound to hyaluronan and consequently eluted early (Fig.4A and B). The $V_{\text {。 }}$ peaks from this associative chromatography were collected and re-chromatographed under dissociative conditions. The elution profiles differed markedly; the aggregating proteoglycans from the non-malformed mandibles eluted in a single peak of large proteoglycans (Fig.4 A), whereas the aggregating proteoglycans from the malformed mandibles eluted in two peaks as large and small proteoglycans (Fig. 4B).

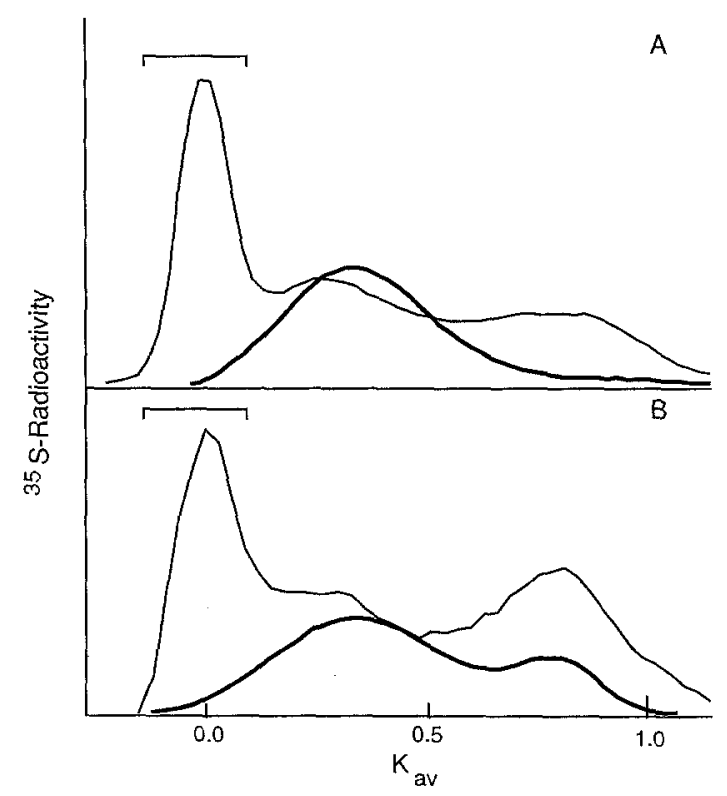

Fig.4. Cartilage guanidine $\mathrm{HCl}$ extracts from the front portion of non-malformed $\mathbf{A}$ and malformed $\mathbf{B}$ mandible, both from 20-dayold fetuses from diabetic rat mothers. Chromatography on Sepharose $\mathrm{CL}-2 \mathrm{~B}$ in associative buffer after incubation with hyaluronan $(-)$. The material under the bars was pooled and re-chromatographed in dissociative extraction buffer (-) 
The polysaccharide chain lengths of the chondroitin sulphate proteoglycans in the guanidine $\mathrm{HCl}$ extracts were estimated by chromatography on Sepharose CL-6B after papain digestion of the core proteins, the $\mathrm{K}_{\mathrm{av}}$ values (range: $0.40-0.44$ ) were found to be unaffected by anatomical region and maternal metabolic state (data not shown).

\section{Discussion}

In the rat model for diabetic pregnancy used in the present investigation, the teratological period for the skeleton has been shown to appear as early as during gestational days $6-10$, corresponding to gestational weeks $2-4$ in human pregnancy [17]. The most frequent skeletal malformation in the offspring of the diabetic rats is a grossly underdeveloped mandible, i.e. micrognathia [10]. It is of considerable interest, therefore, that the estimated teratological time period [18], gestational days $6-10$, both precedes and includes the migration of neural crest cells to the mandibular arch region in the embryo. This migratory process provides the precursor cell population of the future cartilage of Meckel $[19,20]$ and, subsequently, the mandibular bone [21].

While the excised rib cartilage is undoubtably cartilage, clear and uncalcified, the mandibular hard tissue studied is more ambiguous. This tissue is partly calcified and consists of regions of Meckels cartilage, partly resorbed and partly calcified, there are tooth forming regions, and the membrane-bone regions which will also form secondary cartilages. Perhaps it should largely fall under the heading of condroid bone [22]. The proteoglycans extracted from this tissue are, however, mainly cartilage type proteoglycans [3], clearly distinct from tooth [23] or bone [24] proteoglycans.

The aim in the present study was to search for characteristic alterations in the metabolism of proteoglycans in fetal tissue from malformed regions. We have here demonstrated that malformed mandibles exhibit a disturbed metabolism of chondroitin sulphate proteoglycans. The alteration appears closely associated with the malformation since it is not present in rib cartilage or in non-malformed mandibles from fetuses of diabetic rats. The disturbance is in part similar to that previously described for cartilage in adult diabetic rats comprising a shift in the biosynthesis pattern from large to small matrix proteoglycans [3]. Also, there is a similarity to (pre)chondrocyte cultures [25], a higher percentage of proteoglycans being released to the medium from cultures from sensitive/malformed regions. A further indication of disturbed proteoglycan metabolism was the discovery of a class of small aggregating proteoglycans in the guanidine extract of malformed mandibles. This suggests an abnormal catabolism of the large cartilage-specific proteoglycan, aggrecan, in the malformed regions of the mandible and may be important in the pathogenesis of the developmental alterations of the tissue.

The fetal mandible is moulded on the cartilage of Meckel which in turn is formed by neural crest cells that invade this anatomical region during the fourth week of embryogenesis in humans (corresponding approximately to gestational day 10 in rats). Cell migration is regulated by amounts and relative proportions of extracellular matrix proteins such as fibronectin and laminin [26], as well as proteoglycans [27]. While low concentrations of laminin have been demonstrated to be stimulatory for cell motility in vitro, the motility of neural crest cells was strongly reduced at higher concentrations [28]. Interestingly, increased concentrations of laminin have been demonstrated in embryos of diabetic rats [29].

It is premature to make extensive conclusions regarding causal relationships from the combined findings in this and previous studies of defective chondrogenesis in a diabetic environment, but if the migration of the initial neural crest cell population is inhibited, a less than sufficient number of chondrogenic cells may be present in the mandibular arch (presumably less dense the further the distance from their origin) to allow chondrogenesis to proceed normally. In addition, the role of altered epithelialmesenchymal interaction, leading to changes in expression of critical genes and gene families, should be taken into account [30].

In conclusion, the results indicate an association between a cartilage-related congenital malformation, micrognathia, and a disturbance in the metabolism of chondroitin sulphate proteoglycan in the malformed anatomical region.

Acknowledgements. The authors are indebted to Ms. A. Nordin and Ms. P. Wentzel for their help in taking care of animals and to Ms. A. Stark for technical assistance. They also thank Dr. L. Kjellén for helpful advice. This investigation was supported by the Swedish Medical Research Council (Grants no. 12X-7475, 03X-6525), The Bank of Sweden Tercentenary Foundation, The "Expressen" Prenatal Research Foundation, The Swedish Diabetes Association, The Nordisk Insulin Foundation Committee, and The Swedish Hoechst Diabetes Fund.

\section{References}

1. Sternberg M, Cohen-Forterre L, Peyroux J (1985) Connective tissue in diabetes mellitus: biochemical alterations of the intercellular matrix with special reference to proteoglycans, collagens and basement membranes. Diab Metabol (Paris) 11:27-50

2. Kjellén L, Bielefeld D, Höök M (1983) Reduced sulfation of liver heparan sulphate in experimentally diabetic rats. Diabetes 32: 337-342

3. Unger E, Kjellén L, Eriksson UJ (1991) Effect of insulin on the altered production of proteoglycans in rib cartilage of experimentally diabetic rats. Arch Biochem Biophys 285: 205-210

4. Kanwar YS, Linker A, Farquhar MG (1980) Increased permeability of the glomerular basement membrane to ferritin after removal of glycosaminoglycans (heparan sulphate) by enzyme digestion. J Cell Biol 86: 688-693

5. Schwartz NB, Dorfman A (1975) Stimulation of chondroitin sulphate proteoglycan production by chondrocytes in monolayer. Connect Tissue Res 3:115-122

6. Weiss R, Gron A, Nimni M (1981) Abnormalities in the biosynthesis of cartilage and bone proteoglycans in experimental diabetes. Diabetes 30: 670-677

7. Axelsson I, Lorentzon R, Pita J (1983) Biosynthesis of rat growth plate proteoglycans in diabetes and malnutrition. Calcif Tissue Int 35: 237-242

8. Heinze E, Brenner R, Nguyen-Thi $\mathrm{CH}$, Vetter $\mathrm{U}$, Leupold D, Pohlandt $F$ (1986) Skeletal growth in fetal rats, effects of glucose and amino acids. Diabetes 35: 222-227 
9. Heinze E, Vetter U (1987) Skeletal growth of fetuses from streptozotocin diabetic rat mothers: in vivo and in vitro studies. Diabetologia 30: 100-103

10. Eriksson UJ, Dahlström VE, Larsson KS, Hellerström C (1982) Increased incidence of congenital malformations in the offspring of diabetic rats and their prevention by maternal insulin therapy. Diabetes 31:1-6

11. Eriksson UJ (1988) Importance of genetic predisposition and maternal environment for the occurrence of congenital malformations in offspring of diabetic rats. Teratology 37: 365-374

12. Styrud J, Eriksson UJ (1990) Effects of D-glucose and $\beta$-hydroxybutyric acid on the in vitro development of (pre)chondrocytes from embryos of normal and diabetic rats. Acta Endocrinol (Copenh) 122: 487-498

13. Junod A, Lambert AE, Stauffacher W, Renold AE (1969) Diabetogenic action of streptozotocin: relationship of dose to metabolic response. J Clin Invest 48: 2129-2139

14. Sajdera SW, Hascall VC (1969) Protein polysaccharide complex from bovine nasal cartilage. A comparison of low and high shear extraction procedures. J Biol Chem 244: 77-87

15. Kolset SO, Kjellén L, Seljelid R, Lindahl U (1983) Changes in glycosaminoglycan biosynthesis during differentiation in vitro of human monocytes. Biochem J 210: 661-667

16. Winer BJ (1971) Statistical principles in experimental design. McGraw-Hill, New York

17. Mills JL, Knopp RH, Simpson JL et al. (1988) Lack of relation of increased malformation rates in infants of diabetic mothers to glycemic control during organogenesis. N Engl J Med 318: 671676

18. Eriksson RSM, Thunberg L, Eriksson UJ (1989) Diabetes in pregnancy: effects of interrupted insulin treatment on the fetal outcome of the pregnant rat. Diabetes 38: 764-772

19. Le Lievre CS (1978) Participation of neural crest-derived cells in the genesis of the skull in birds. J Embryol Exp Morph 47:17-37

20. Hall BK (1980) Chondrogenesis and osteogenesis in cranial neural crest cells. In: Pratt R, Christiansen RL (eds) Current research trends in prenatal craniofacial development. Elsevier, Amsterdam New York, pp 47-63

21. Hall BK (1980) Tissue interactions and the initiation of osteogenesis and chondrogenesis in the neural-crest derived mandibu- lar skeleton of the embryonic mouse as seen in isolated murine tissues and in recombinations of murine and avian tissue. J Embryol Exp Morph 58: 251-264

22. Hall BK (1983) Tissue interactions and chondrogenesis. In: Hall BK (ed) Cartilage, development, differentiation, and growth. Academic Press, New York, pp 187-222

23. Endo N (1989) Isolation and characterization of proteoglycan in bovine periodontal ligament. Kanagawa Shigaku 24: 207-218

24. Fisher LW, Termine JD, Dejter SW Jr et al. (1983) Proteoglycans of developing bone. J Biol Chem 258: 6588-6594

25. Styrud J, Unger E, Eriksson UJ (1990) Metabolism in vitro of cartilage proteoglycans in rat (pre)chondrocytes from different embryonic regions. Ups J Med Sci 95: 31-44

26. Zetter BB, Brightman SE (1990) Cell motility and the extracellular matrix. Current Op Cell Biol 2: 850-856

27. Lane MC, Solursh M (1991) Primary mesenchyme cell migration requires a chondroitin sulphate/dermatan sulphate proteoglycan. Develop Biol 143: 389-397

28. Perris R, Johansson S (1987) Amphibian neural crest cell migration on purified extracellular matrix components: a chondroitin sulphate proteoglycan inhibits locomotion on fibronectin substrates. J Cell Biol 105: 2511-2521

29. Sala R, Cagliero E, Lozenzi M, Eriksson UJ (1990) Increased expression of laminin-B1 in embryos of diabetic rats. Diabetologia 33: A138 (Abstract)

30. Takahashi Y, Bontoux M, Le Douarin NM (1991) Epitheliomesenchymal interactions are critical for Quox 7 expression and membrane bone differentiation in the neural crest derived mandibular mesenchyme. EMBO J 10: 2387-2393

Received: 25 October 1991

and in revised form: 28 January 1992

Dr. E. Unger

Department of Veterinary Medical Chemistry

Swedish University of Agricultural Sciences

The Biomedical Centre

P.O. Box 575

S-75123 Uppsala

Sweden 